\title{
THE PERMEABILITY OF GASES THROUGH REACTING SOLUTIONS: THE CARBON DIOXIDE-BICARBONATE MEMBRANE SYSTEM
}

\author{
SHYAM R SUCHDEO and JEROME S SCHULTZ \\ Department of Chemical Engineering, The University of Michigan, \\ Ann Arbor, Michigan 48104, U S A
}

(Recelved 22 November 1972, in revised form 16 May 1973)

\begin{abstract}
The transport of a gas across a stationary liquid film containing reactive species is investigated for the purpose of determining gas permeabilities or mass transfer coefficients in reacting solutions Under limiting conditions when the reaction time constant far exceeds the diffusional time constant, the flux of the transported gas follows Fick's law of diffusion Analytical series solution for the contribution of the chemical reaction to the transport process is obtained using the technique of perturbation analysis, criteria for the validity of various terms in the series solution are presented The permeability of carbon dioxide in water and in $1 \mathrm{~N} \mathrm{NaHCO}_{3}-\mathrm{Na}_{2} \mathrm{CO}_{3}$ solution is estımated It is shown that a high degree of accuracy in the data is necessary for obtaining separate estımates of diffusivity and solubility by this technique
\end{abstract}

\section{INTRODUCTION}

Several industrial processes involve gas absorption accompanied by chemical reaction, in the design of such equipment, pertinent information regarding diffusivity and physical solubility of the gas in the reactıng solution is often necessary A few semiempincal correlations for predicting the same, based on mass transfer in non-reacting solutions, have been reported in the literature [1-3] The absorption of carbon dioxide in $\mathrm{HCO}_{3}{ }^{-} / \mathrm{CO}_{3}{ }^{2-}$ solution (ronic strength 1-3 gmion/l) has been studied for determining $\sqrt{D} C^{*}$ (where $D$ is the diffusivity and $C^{*}$ is the physical solubility) using equipment of known surface area, such as the wetted-wall column [4, 5] and rotatıng drum [6] The analysis in these studies conformed to the assumption that the reactions were irreversible

In this article, an experimental approach is outlined for estımating the permeability (product of diffusivity and solubility) of gases in reacting solutions The concept of permeability defined here is similar to, but not the same as, that of classical mass transfer coefficient in the film thcory Use is made of the fact that under a limiting condition, the contribution of the chemical reaction to the overall absorption process may be negligible This limiting condition is realized whenever the time constant or the relaxation time for the chemical reaction is much larger than that for the diffusion process, the necessary criterion for such a condition is described The analysis presented here is limited to reversible reactions and one transferred (gas) species

A similar concept has been described by Danckwerts [7] for the experimental determination of volumetric mass transfer coefficient, $k_{\mathrm{L}} a^{\prime}$, in absorption equipment However, as Danckwerts has stated, "the condition for no-reaction in the film can be quite restrictive when the mass transfer coefficient is low"[7] In the procedure described here, the film thickness is under direct experimental control, and the no-reaction condition has a greater possibility of being satısfied

\section{MODEL DESCRIPTION AND ANALYSIS}

The process governing the mass transfer, accompanied by reversible chemical reaction, of a gas across immobilized layers of liquid films or membranes falls under the category of 'facilitated' diffusion Such systems have been studied for a number of years in the biological field, the model studies beginning with the transport of oxygen across layers of hemoglobin solutions $[8,9]$ are the most germaine here Although a comparatively large amount of literature has collected in this field (biological and otherwise), published literature on the industrial use of the 'facilitated' diffusion phenomenon in the separation of gases remains mummal

\section{Steady-state diffusion of a reacting gas across a planar liquid film \\ Consider the diffusion of a dissolved gas, $A_{1}$, ac- ross a hquid film of thickness $L$ The film contains}


'reacting' species, $A_{2}$ and $A_{3}$, which react with $A_{1}$ as shown in Fig 1 A partial pressure driving force in species $A_{1}$, namely $\bar{p}-\underline{p}$, is maintained across the liquid film Typıcal concentration profiles $\left(C_{1}\right)$ for the various species are also depicted in Fig 1 Several species $\left(A_{t}, \imath=2,3, \quad, n\right)$ may participate in other reactions, however, only the reaction involving apecies $A_{1}$ is considered rate limiting in terms of kinetics of the reaction

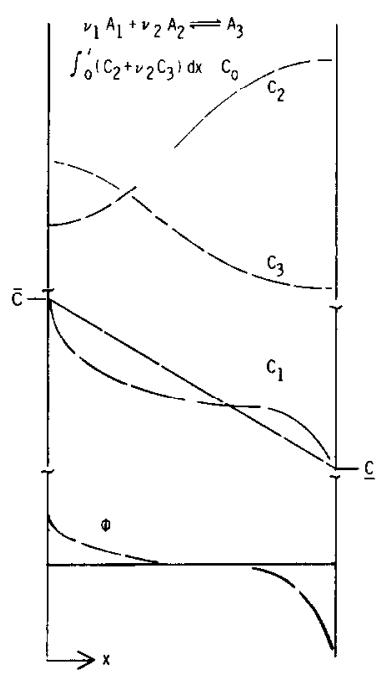

Fig 1 Concentration and reaction profiles withın a film

Allowing for "dilute" solutions and binary diffusion coefficients, the governing one-dimensional diffusion-reaction equations at steady state, and the appropriate boundary conditions are

$$
\frac{D_{1}}{\nu_{1}} \frac{\mathrm{d}^{2} \hat{C}_{1}}{\mathrm{~d} y^{2}}=\frac{D_{2}}{\nu_{2}} \frac{\mathrm{d}^{2} \hat{C}_{2}}{\mathrm{~d} y^{2}}=-D_{3} \frac{\mathrm{d}^{2} \hat{C}_{3}}{\mathrm{~d} y^{2}}=-r_{3}
$$

and

$$
\begin{aligned}
& @ y=0, \hat{C}_{1}=\hat{C}_{1}(0), \frac{\mathrm{d} \hat{C}_{2}}{\mathrm{~d} y}=\frac{\mathrm{d} \hat{C}_{3}}{\mathrm{~d} y}=0 \\
& @ y=L, \hat{C}_{1}=\hat{C}_{1}(1), \frac{\mathrm{d} \hat{C}_{2}}{\mathrm{~d} y}=\frac{\mathrm{d} \hat{C}_{3}}{\mathrm{~d} y}=0
\end{aligned}
$$

Only three of the four boundary conditions on the non-transferred are independent since one must satisfy the storchiometric relationship for the "non-transferred" species, $A_{2}$ and $A_{3}$

$$
\frac{1}{L} \int_{0}^{L}\left(\hat{C}_{2}+\nu_{2} \hat{C}_{3}\right) \mathrm{d} y=\hat{C}_{2}^{r}
$$

At this stage, the diffusion-reaction equations and the boundary conditions are transposed to a dimensionless form in order to examıne the relatıve importance of diffusion and chemical reaction terms Thus,

$$
\frac{\mathrm{d}^{2} C_{\mathrm{t}}}{\mathrm{d} x^{2}}=g_{\imath} \alpha^{2} \phi
$$

where

$$
\begin{aligned}
\alpha^{2} & =k * C *{ }^{p} L^{2} / D * \\
\phi & =-r_{3} / k_{*} C_{*}^{p+1} \\
C_{1} & =\hat{C}_{l} / C * \\
x & =y / L \\
g_{1} & =D \cdot \nu_{1} / D_{1}, g_{2}=D * \nu_{2} / D_{2}, g_{3}=-D * / D_{3}
\end{aligned}
$$

and $C_{*}, D$. and $k_{*}$ are typical concentration, diffusivity and reaction rate constant, respectively The dimensions of $k \cdot C_{*}^{p}$ are $[\mathrm{sec}]^{-1}$

The steady-state flux of $A_{1}$ across the liquid film, $N_{1}$, is given by

$$
N_{\mathrm{l}}=-\frac{D_{1} C_{*}}{L}\left[\frac{\mathrm{d} C_{1}}{\mathrm{~d} x}\right]_{x=0}
$$

Defining $N_{0}$ as the Fickian flux, that is, the flux obtained under conditions of physical absorption,

$$
N_{0}=\frac{D_{1} C_{*}}{L}(\bar{C}-\underline{C})
$$

we have

$$
\frac{N_{1}}{N_{0}}=\frac{-1}{(\bar{C}-C)}\left[\frac{\mathrm{d} C_{1}}{\mathrm{~d} x}\right]_{x=0}
$$

where

$$
\begin{aligned}
& \bar{C}=\hat{C}_{1}(0) / C * \\
& \underline{C}=\hat{C}_{1}(1) / C *
\end{aligned}
$$

The variable $\alpha$ is a measure of diffusion and reaction resistances For first order irreversible reaction in a slab of thickness $L, \alpha$ is related to the halftimes for diffusion, $t_{D}$, and reaction, $t_{R}$, by a constant [10]

$$
\alpha^{2} \simeq 35 t_{D} / t_{R}
$$

For more complex reactions, such a simple correspondence may not be observed

In a previous paper[11], two limiting regimes were defined based on the relative magnitude of reaction and diffusion terms

$$
\begin{aligned}
& \alpha \rightarrow 0 \\
& \alpha \rightarrow \infty
\end{aligned} \quad \text { "Near diffusion" regime }
$$


We are concerned here with the near diffusion regime in which the flux of the transported species in excess of its diffusional flux is small compared to that excess realized when all reactions are at equilibrium, that is,

$$
N_{1}-N_{0} \ll N_{1}^{E}-N_{0}
$$

where $N_{1}{ }^{E}$ is the flux of the transported species under the conditions of reaction equilibrium

A similar limiting condition is described by Danckwerts [7] for gas absorption with chemical reaction of species $A_{1}$ in bulk of the liquid For a first-order irreversible reaction, "the condition that a negligible amount of gas absorbed should react in the film" is given by [7]

$$
\frac{D_{t} k}{k_{L}^{2}} \ll 1
$$

where $k$ is the first order rate constant and $k_{L}$ is the mass transfer coefficient

Asymptotic solution in the near diffusion regime

An asymptotic solution to the diffusion-reaction equations for the limit $\alpha \rightarrow 0$ is derived below The solution is non-singular, that is, valid in the entire distance field, $0 \leq x \leq 1$ Utilizing the techniques of perturbation theory, the concentration profiles are postulated to be of the form

$$
C_{t}=C_{t}^{(0)}+\alpha^{2} C_{t}^{(1)}+\alpha^{4} C_{t}^{(2)}+
$$

The dimensionless reaction-rate term $\phi$ is expanded in a Taylor series around $C_{1}^{(0)}$ Subsequent substitution of Eq (8) in the Taylor series for $\phi$ gives

$$
\phi=\phi^{(0)}+\alpha^{2} \sum_{j=1}^{3} \phi^{\prime} C_{1}^{(1)}+
$$

where

$$
\begin{gathered}
\phi^{(0)}=[\phi]_{C_{1}=C_{\mathrm{t}}^{(0)}} \\
\phi^{\prime}-\left[\frac{\partial \phi}{\partial C_{\jmath}}\right]_{C_{1}=C_{1}^{(0)}}
\end{gathered}
$$

The flux of the diffusing species $A_{1}$ relative to its Fickian flux is given by

$$
\frac{N_{1}}{N_{0}}=-\frac{1}{(\bar{C}-\underline{C})} \sum_{j=0}^{p} \alpha^{2 j}\left[\frac{\mathrm{d} C_{1}^{(p)}}{\mathrm{d} x}\right]_{x=0}+0\left(\alpha^{2 p+2}\right)
$$

Substıtutıng Eqs (8) and (9) into Eq (4), and equat- ing terms in like powers of $\alpha$, we have

$$
\frac{\mathrm{d}^{2} C_{1}^{(p)}}{\mathrm{d} x^{2}}=g_{i} \delta^{(p)}
$$

where

$$
\begin{aligned}
& \delta^{(0)}=0, \\
& \delta^{(1)}=\phi^{(0)}, \\
& \delta^{(2)}=\sum_{j=1}^{3} \phi^{j} C_{j}^{(1)}, \text { etc }
\end{aligned}
$$

Since the final solution to the problem must satisfy the boundary conditions and the stoichiometric relationship for any degree in $\alpha$, we may choose to assure consistency by requiring

$$
\begin{array}{lc}
@ x=0 & C_{1}^{(0)}=\bar{C} \\
@ x=1 & C_{1}^{(0)}=C \\
@ x=0,1 & \frac{\mathrm{d} C_{2}^{(0)}}{\mathrm{d} x}=0=\frac{\mathrm{d} C_{3}^{(0)}}{\mathrm{d} x} \\
\int_{0}^{1}\left(C_{2}^{(0)}+C_{3}^{(0)}\right) \mathrm{d} x=C_{0}
\end{array}
$$

and

$$
\begin{array}{cc}
@ x=0,1 & C_{1}^{(p)}=0 \\
@ x=0,1 & \frac{\mathrm{d} C_{2}^{(p)}}{\mathrm{d} x}=0=\frac{\mathrm{d} C_{3}^{(p)}}{\mathrm{d} x} \\
& \int_{0}^{1}\left(C_{2}^{(p)}+C_{3}^{(p)}\right) \mathrm{d} x=0
\end{array}
$$

where $C_{0}=\hat{C}_{2}{ }^{T} / C_{*}$, and $p=1,2$,

The non-linear set of diffusion-reaction equations, Eq (4), has been reduced to a series of ordinary linear differential equations, $\mathrm{Eq}$ (11), since for any degree of approximation $p, \delta^{(p)}$ is determined from the $(p-1)$ th approximation The zero-order solution to $\mathrm{Eq}(11)$, that is, for $p=0$, is

$$
\begin{aligned}
C_{1}^{(0)} & =\bar{C}-(\bar{C}-C) x \\
C_{1}^{(0)} & =\gamma_{1}^{(0)}, l=2,3
\end{aligned}
$$

where $\gamma_{t}^{(0)}$ are constants of integration

Note that the zero-order solution, Eq (14), predicts zero facilitation (or enhancement) in the flux of $A_{1}$ For $p>1$, the solution to Eq (11) may be written in the following generalızed form

$$
\begin{gathered}
C_{i}^{(p)}=g_{i} \lambda^{(p)}+\epsilon_{t}^{(p)} x+\gamma_{1}^{(p)} \\
{\left[\frac{\mathrm{d} C_{l}^{(p)}}{\mathrm{d} x}\right]_{x=0}=g_{1}\left(f_{0}^{(p)}+\lambda_{0}^{(p)}-\lambda_{1}^{(p)}\right)}
\end{gathered}
$$


where

$$
\begin{aligned}
& f^{(p)}=\int \delta^{(p)} \mathrm{d} x, \\
& \lambda^{(p)}=\int f^{(p)} \mathrm{d} x,
\end{aligned}
$$

and $\epsilon_{1}^{(p)}$ and $\gamma_{1}^{(p)}$ are constants of integration Subscripts 0,1 on $f^{(p)}$ and $\lambda^{(p)}$ denote evaluation at $x=0,1$, respectively Equation (10) may therefore be written as

$$
\begin{aligned}
\frac{N_{1}}{N_{0}}=1 & +\frac{g_{1}}{(\bar{C}-C)} \\
& \times \sum_{j=1}^{p} \alpha^{2 j}\left(\lambda_{1}^{(j)}-\lambda_{0}{ }^{(j)}-f_{0}^{(j)}\right)+0\left(\alpha^{2 p+2}\right)
\end{aligned}
$$

Writing the flux equation in this form, we can see that the estimate of permeability is obtained from the experimental determination of $N_{1}$ when the condition $\alpha \rightarrow 0$ is satisfied since

$$
\underset{\alpha \rightarrow 0}{\operatorname{Limit}} N_{1}=N_{0}
$$

The major theoretical question is to find a criterion for the magnitude of $\alpha$ that would permit the extrapolation of $N_{1}$ to $N_{0}$ at $\alpha=0$ This is determined by evaluating the various terms in the expansion series, $\mathrm{Eq}$ (17)

In as much as the first term in Eq (17), $\mathrm{j}=1$, dominates the series, a linear extrapolation may be made in a plot of $\left[\left(N_{1} / N_{0}\right)-1\right]$ vs $\alpha^{2}$ The secondorder correction term in $\mathrm{Eq}(17), j=2$, is meaningful only in that a criterion for the validity of the first-order correction term is made avalable

The reader may easily verify that for any generalized reaction rate which is first-order in the transferred species $A_{1}$, namely, kinetic function of the form (where $S$ is any function of $C_{2}, C_{3}$ )

$$
\phi=\frac{C_{1} C_{2}{ }^{m}-C_{3}{ }^{n} K}{S\left(C_{2}, C_{3}\right)}
$$

one always obtains

$$
f_{0}^{(j)}=\lambda_{0}{ }^{(j)}=0, J=1,2, \quad,
$$

and $\mathrm{Eq}(17)$ reduces to the following simpler form

$$
\begin{gathered}
\left(\gamma_{3}^{(0) n}\right) /\left(\gamma_{2}{ }^{(0) m}\right)=\frac{(\bar{C}+C) K}{2} \\
\frac{N_{1}}{N_{0}}=1+\frac{g_{1}}{(\bar{C}-C)} \sum_{j=1}^{p} \alpha^{21} \lambda_{1}{ }^{(1)}+0\left(\alpha^{2 p+2}\right)
\end{gathered}
$$

Note that $\gamma_{2}{ }^{(0)}$ and $\gamma_{3}{ }^{(0)}$, as indicated by Eq (21), are equilibrium values for $C_{2}$ and $C_{3}$ determined at the arithmetic average concentration of the transferred species $A_{1}$ at the two interfaces ( $x=0$ and $x=1$ ) A similar analysis for the specific case of oxygen facilıtation across thin hemoglobin film is given by Smith et al [12]

With a knowledge of the kinetics of the reaction and approximate value for the kinetic constants, one can evaluate the first few terms of the series indicated in Eq (22) This can then be utilized to determine the experimental range of parameters required to estimate $N_{0}$ by extrapolation of Eq (22) to $\alpha=0$ The procedure is illustrated in the following example

\section{EXAMPLE $\mathrm{CO}_{2} / \mathrm{HCO}_{3}^{-} / \mathrm{CO}_{3}{ }^{2-}$ SYSTEM}

The diffusion of carbon dioxide across a liquid film containing $\mathrm{HCO}_{3}{ }^{-} / \mathrm{CO}_{3}{ }^{2-}$ is investigated herein The rate controlling reactions for the process are

$$
\begin{gathered}
\mathrm{CO}_{2}+\mathrm{H}_{2} \mathrm{O} \underset{k_{-1}}{\stackrel{k_{1}}{\rightleftharpoons}} \mathrm{H}^{+}+\mathrm{HCO}_{3}{ }^{-} \\
\mathrm{CO}_{2}+\mathrm{OH}^{-} \underset{k_{-2}}{\stackrel{k_{2}}{\rightleftharpoons}} \mathrm{HCO}_{3}{ }^{-}
\end{gathered}
$$

The following very fast reactions are assumed to be at equilibrium

$$
\begin{gathered}
\mathrm{HCO}_{3}{ }^{-} \rightleftharpoons \mathrm{H}^{+}+\mathrm{CO}_{3}{ }^{2-}, \mathrm{K}_{3} \\
\mathrm{H}_{2} \mathrm{O} \rightleftharpoons \mathrm{H}^{+}+\mathrm{OH}^{-}, \mathrm{K}_{w}
\end{gathered}
$$

The rate of depletion of carbon dioxide is given by [13]

$$
r_{1}=k_{1} \hat{C}_{1}-k_{-1} K_{3} \frac{\hat{C}_{3}^{2}}{\hat{C}_{2}}+\frac{k_{2} K_{w}}{K_{3}} \frac{\hat{C}_{1} \hat{C}_{2}}{\hat{C}_{3}}-k_{-2} \hat{C}_{3}
$$

which may be rearranged as follows

$$
r_{1}=k_{1}\left(1+n \frac{2 \hat{C}_{2}}{\hat{C}_{3}}\right)\left(\hat{C}_{1}-\frac{1}{K} \frac{\hat{C}_{3}{ }^{2}}{\hat{C}_{2}}\right)
$$

where

$$
\begin{gathered}
n=\frac{k_{2} K_{w}}{2 k_{1} K_{3}} \\
K=\frac{k_{1}}{k_{-1} K_{3}}
\end{gathered}
$$

(Subscripts $1,2,3$, on $\hat{C}_{1}$ and $D_{1}$ refer to $\mathrm{CO}_{2}, \mathrm{CO}_{3}{ }^{2-}$, $\mathrm{HCO}_{3}^{-}$respectıvely) Definıng

$$
\begin{aligned}
x & =y / L \\
C_{1} & =\hat{C}_{1} / \hat{C}_{1}(0), C_{2}=\hat{C}_{2} / \hat{C}_{3}{ }^{T}, C_{3}=\hat{C}_{3} / \hat{C}_{3}{ }^{\top}
\end{aligned}
$$




$$
\begin{aligned}
& \alpha^{2}=k_{1} L^{2} / D_{1} \\
& g_{1}=1, g_{2}=\frac{D_{1} \hat{C}_{1}(0)}{D_{2} \hat{C}_{3}{ }^{T}}, g_{3}=\frac{-2 D_{1} \hat{C}_{1}(0)}{D_{3} \hat{C}_{3}{ }^{T}} \\
& \phi=\left(1+n \frac{2 C_{2}}{C_{3}}\right)\left(\bar{C}_{1}-m \frac{C_{3}{ }^{2}}{2 C_{2}}\right) \\
& m=2 \hat{C}_{3}{ }^{T} / K \hat{C}_{1}(0)
\end{aligned}
$$

we have

$$
\frac{\mathrm{d}^{2} C_{1}}{\mathrm{~d} x^{2}}=g_{1} \alpha^{2} \phi
$$

For $D_{\mathrm{HCO}_{3}{ }^{-}} \simeq D_{\mathrm{CO}_{3}{ }^{2-}}$, the solution of Eq (26) for $\alpha \rightarrow 0$ 1s as follows (see Appendix 1)

$\frac{N_{1}}{N_{0}}=1+\frac{1}{12} Y_{0} \alpha^{2}-\frac{Y_{0}}{720}\left[Y_{0}+g_{2} Y_{1}\left(6-\frac{a^{2} \zeta^{2}}{2}\right)\right] \alpha^{4}$

where

$$
\begin{aligned}
Y_{0} & =1+2 n \frac{\gamma_{2}^{(0)}}{\gamma_{3}{ }^{(0)}} \\
Y_{1} & =m Y_{0}\left[1-\frac{1}{\left(1-\gamma_{3}{ }^{(0)}\right)^{2}}\right] \\
Y_{2} & =n / \gamma_{3}{ }^{(012} \\
\zeta & =Y_{2} / Y_{1} \\
a & =-(1-\rho)
\end{aligned}
$$

and

$$
N_{o}=D_{1} H_{1} \bar{p}(1-\rho) / L\left(\bar{p} H_{1}=\hat{C}_{1}(0), \rho=\underline{p} / \bar{p}\right)
$$

$\gamma_{2}{ }^{(0)}$ and $\gamma_{3}{ }^{(0)}$ are related by the following two equatrons

$$
\begin{gathered}
2 \gamma_{2}{ }^{(0)}+\gamma_{3}{ }^{(0)}=1 \\
\gamma_{3}{ }^{(0) 2} / \gamma_{2}{ }^{(0)}=\frac{1+\rho}{m}
\end{gathered}
$$

In an earlier paper by Otto and Quinn[13] on carbon dıoxide facilitation through $\mathrm{CO}_{3}{ }^{2-}$ films, an approximate solution to the diffusion-reaction equations was obtained on the assumption that the concentration of $\mathrm{HCO}_{3}{ }^{-}$and $\mathrm{CO}_{3}{ }^{2-}$ was nearly constant throughout the film The facilitation in the flux so obtained by them, as Eq (27) in their paper [13] is equivalent to the first term in $\mathrm{Eq} 27$ namely

$$
\frac{1}{12} Y_{0} \alpha^{2}
$$

(see Appendix 2)
For large values of $(1+\rho / m)$, Eqs (28a) and (28b) may be approximated to

$$
\begin{aligned}
& \gamma_{3}{ }^{(0)} \simeq 1-\frac{2 m}{1+\rho} \\
& \gamma_{2}{ }^{(0)} \simeq \frac{m}{1+\rho}
\end{aligned}
$$

Thus,

$$
\begin{aligned}
& Y_{0} \simeq 1+\frac{2 m n}{1+\rho} \\
& Y_{1} \simeq-\frac{(1+\rho)^{2}}{4 m} Y_{0} \\
& Y_{2} \simeq \frac{n}{\left[1-\frac{4 m}{1+\rho}\right]}
\end{aligned}
$$

The following literature values are used to evaluate $m$ and $n$ for a $1 \mathrm{~N} \mathrm{NaHCO}_{3}-\mathrm{Na}_{2} \mathrm{CO}_{3}$ solution $\left(\hat{C}_{3}{ }^{T}=\right.$ $10^{-3} \mathrm{moles} / \mathrm{cm}^{3}$ )

$$
\begin{array}{rl}
k_{1} & 00375 \mathrm{sec}^{-1}[14] \\
\frac{k_{2} K_{\mathrm{w}}}{\bar{K}_{3}} & 086 \mathrm{sec}^{-1}[5] \\
K H_{1} & 01050 \mathrm{moles} / \mathrm{cm}^{3}, \operatorname{atm}[15] \\
D_{2} & 089 \times 10^{-5} \mathrm{~cm}^{2} / \mathrm{sec}[16]
\end{array}
$$

Figure 2 shows a typical variation of facilitation factor, $F$, with respect to $\alpha^{2}$ where

$$
F=\frac{N_{1}}{N_{0}}-1
$$

The numerical solution to $\mathrm{Eq}$ (26), based on a quasilinearization technique described in an earlier paper[11], is also included in Fig 2 The magnitude of the first and second order correction terms at varıous values of carbon dioxide partial pressure at $x=0(\bar{p})$ are given in Table 1 Also included in Table 1 is the critical value $\alpha_{c}^{2}$ defined as that $\alpha^{2}$ for which the second order correction term contribution is equal to 10 per cent of the first order term contribution, that is

$$
\alpha_{c}^{2}=01 \frac{M}{N}
$$

Therefore, for $\alpha<\alpha_{c}$, the second order correction term may be neglected 
Table 1

\begin{tabular}{llll}
\hline \multicolumn{4}{c}{$F=M \alpha^{2}-N \alpha^{4}$} \\
\hline \multicolumn{3}{c}{ Correction terms (first and second) of Eq (27) } \\
\hline $\begin{array}{llll}\rho=001 \\
m=0019 / \bar{p}\end{array}$ & & & \\
$n=1145$ & & & \\
$-g_{3}=0086 \bar{p}$ & & & \\
$\bar{p}$, atm & 01156 & 00226 & 0551 \\
1 & 01350 & 00164 & 083 \\
$2 / 3$ & 01820 & 00132 & 138 \\
$1 / 3$ & 03637 & 00305 & 119 \\
$1 / 10$ &
\end{tabular}

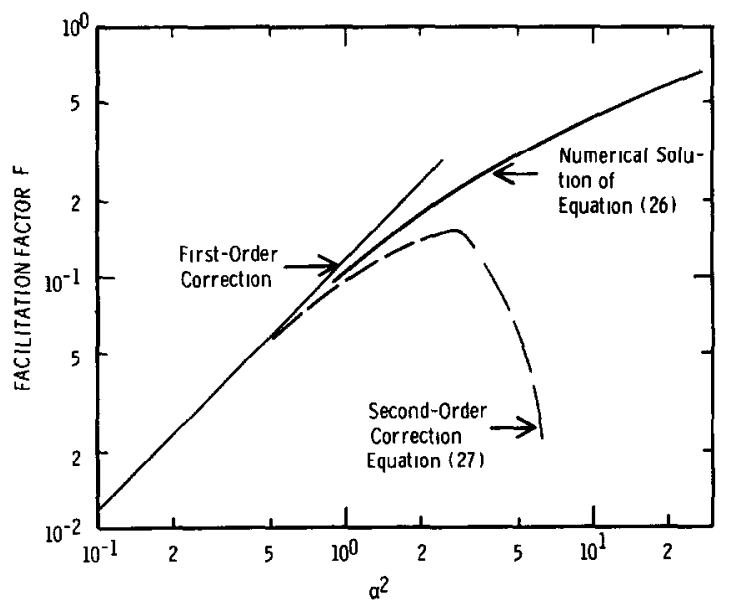

Fig 2 Facilitation factor as a function of $\alpha^{2}$, the ratio of diffusion to reaction resistance

As is evidenced from the numbers given in Table 1, the perturbation solution, Eq (27), remains convergent for $\alpha$ in the vicinity of unity and for signifcant, though small, facilitation The criterion for the convergence of the perturbation model is not that

$$
M \alpha^{2} \ll 1
$$

but

$$
N \alpha^{4} \ll M \alpha^{2}
$$

that is, the convergence of $F$, and not $N_{1} / N_{0}$, is desired For the purpose of estımating $D_{1}$ and $H_{1}$, Eq (27) may be rearranged as follows

$$
\frac{N_{1} L}{\bar{p}-\underline{p}}=D_{1} H_{1}+\frac{1}{12} H_{1} Y_{o}\left(k_{1} L^{2}\right)+
$$

In Eq (30), $N_{1} L /(\bar{p}-p)$ may be recognized as the

${ }^{*}$ Gelman Instruments Company
Table 2 Permeability of carbon dioxide in $1 \mathrm{~N}$ $\mathrm{NaHCO}_{3}-\mathrm{Na}_{2} \mathrm{CO}_{3}$ solution

\begin{tabular}{cc}
\hline $\begin{array}{c}D_{1} H_{1} \times 10^{10} \\
\text { moles } / \mathrm{cm}, \text { atm, sec }\end{array}$ & Source \\
\hline 420 & {$[3,22]$} \\
435 & {$[3,4]$} \\
457 & {$[3,1]$} \\
$38 \pm 01$ & This work \\
\hline
\end{tabular}

effective permeability of carbon dioxide through the $\mathrm{HCO}_{3}{ }^{-} / \mathrm{CO}_{3}{ }^{2-}$ film

From the values given in Table 2, as long as $\alpha^{2}$ is less than $\alpha_{c}^{2}$, the permeability data may be linearly extrapolated to find $D_{1} H_{1}$ by Eq (30)

\section{EXPERIMENTAL METHODS AND RESULTS}

The experimental setup used in this study is identical to the one described by Bassett and Schultz [17] The liquid film, constructed by soakıng a highly porous cellulose acetate membrane (porosity $85 \%)^{*}$ in the test solution, is held firmly between two chambers of a diffusion cell On the "upstream" side, a mixture of carbon dioxide and nitrogen (latter to obtain the desired carbon dioxide partial pressure) is passed continually at $20-40 \mathrm{~cm}^{3}$ per min On the "downstream"' side, helium is used to sweep away the carbon dioxide that may have diffused across the liquid film The total pressure in the entirc apparatus is one atmosphere, all gases are saturated with water vapor prior to entry into the diffusion cell Gas streams are analyzed by chromatography, and the flow rates measured with a $10 \mathrm{~cm}^{3}$ soap bubble flow meter The steady state transport rate of carbon dioxide across the membrane is estımated from the measured flow rate and composition of the "downstream" side

The results of diffusion experıments for films containing water and $1 \mathrm{~N}$ sodium bicarbonate are shown in Figs 3 and 4 In all the experimental runs reported here, the "downstream" carbon dioxide partial pressure was small

$$
p \sim 001 \tilde{p}
$$

For transport across the water film, the proportionality between the carbon dioxide flux and its partial pressure driving force is observed, the Fick's Law of diffusion gives

$$
\frac{V_{1}}{(\bar{p}-\underline{p})}=\frac{D_{i}^{\circ} H_{1}^{\circ}\left(A_{m} P\right)}{\left(L_{m} \tau\right)} \frac{v}{60} \mathrm{~cm}^{3} / \mathrm{min}, \text { atm }
$$


where

$V_{1}$ is the flux of carbon dioxide, $\mathrm{cm}^{3} / \mathrm{min}$

$A_{m}$ is the membrane transfer area, $=155 \mathrm{~cm}^{2}$

$P$ is the membrane porosity, $=088$

$v$ is the molar volume at $25^{\circ} \mathrm{C}$, =

$24,450 \mathrm{~cm}^{3} /$ gmole

$L_{m}$ is the measured membrane thickness, = $162( \pm 11) \times 10^{-4} \mathrm{~cm}$

$\tau$ is the tortuosity of the membrane (unknown)

A least-squares fit through the origin for the data in Fig 3 gives

$$
D_{\mathrm{i}} H_{\mathrm{i}} / \tau=551 \times 10^{-10} \mathrm{gmoles} / \mathrm{cm}, \mathrm{atm}, \mathrm{sec}
$$

The literature values for $H_{1}^{\circ}$ is $339 \times$ $10^{-5} \mathrm{moles} / \mathrm{cm}$, atm [18] and that for $D_{1}$ ranges from $185-200 \times 10^{-5} \mathrm{~cm}^{2} / \mathrm{sec}[18,19,20]$ Using a water film entrapped between two plastic films instead of the membrane soaked film employed in this study, Otto and Quinn[13] obtained a carbon dioxide permeability value of $662 \times 10^{-10} \mathrm{gmoles} / \mathrm{cm}$, atm, sec One therefore is inclined to believe that the said difference lies in the fact that the tortuosity of the porous membrane used in this study is considerably higher than unity Wittenberg[21] in his experiments on transfer of nitrogen and oxygen across hemoglobin solutions reports that the observed permeability (calculated as $D_{i}^{\circ} H_{i}^{\circ} P / \tau$ ) of nitrogen across a water-soaked Millipore membrane was $84 \times$ $10^{-12}$ gmoles $/ \mathrm{cm}$, atm, sec $[18,20]$ Assuming that the porosity of the Gelman membrane and the Millpore membrane are the same order of magnitude, one estımates the tortuosity of the Millipore mem-

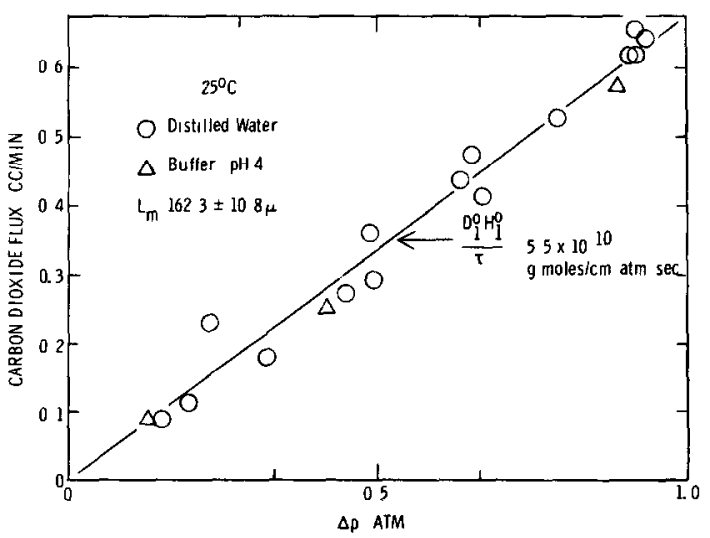

Fig 3 Flux of carbon dıoxıde across a water film brane to be 137 In a simılar experımental set up, Bassett and Schultz using a tortuosity of 1 obtained a diffusivity value, at $25^{\circ} \mathrm{C}$, for oxygen and nitrogen of $201 \times 10^{-5} \mathrm{~cm}^{2} / \mathrm{sec}$ [17] The corresponding literature values range between $187-325 \times 10^{-5}$ and $18-225 \times 10^{-5} \mathrm{~cm}^{2} / \mathrm{sec}$, respectively [20]

Based on a permeability value of $66 \pm 02 \times$ $10^{-10}$ gmoles/cc, atm, sec, the tortuosity and, hence, the diffusion path length, $L$, of the Gelman membrane was calculated

$$
\begin{aligned}
L & =L_{m} \tau \\
& =200( \pm 20) \mu \text { pcr membranc }
\end{aligned}
$$

That the carbon dioxide flux across the water film was not facilitated by the bicarbonate reactions can be demonstrated by measuring the carbon dioxide flux across an acıdıc film, the results of such a measurement across a buffer solution, $\mathrm{pH} \mathrm{4,} \mathrm{are}$ also included in Fig 3

In Fig 4, the two separate lines for $L=006 \mathrm{~cm}$ represent data obtained on two different occasions Although the data for other values of thickness were also obtaned on various occasions, the closeness of the data followed a single least-squares line fit for a given $L$ At $L=006 \mathrm{~cm}$, the difference in the two sets of data warranted that each be described by a least-square line separately The discrepancy in this data remains unexplained From the data reported in Fig 4, the carbon dioxide fluxes at a partial pressure differential across the

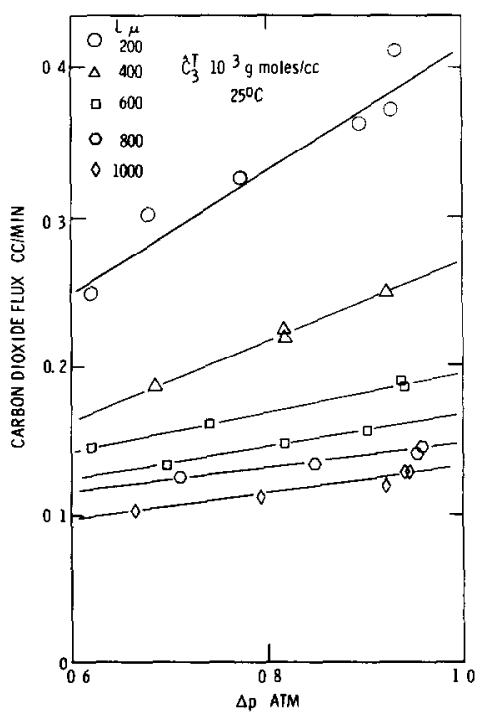

Fig 4 Flux of carbon dioxide across a IN $\mathrm{NaHCO}_{3}-\mathrm{Na}_{2} \mathrm{CO}_{3}$ film for various diffusion lengths 


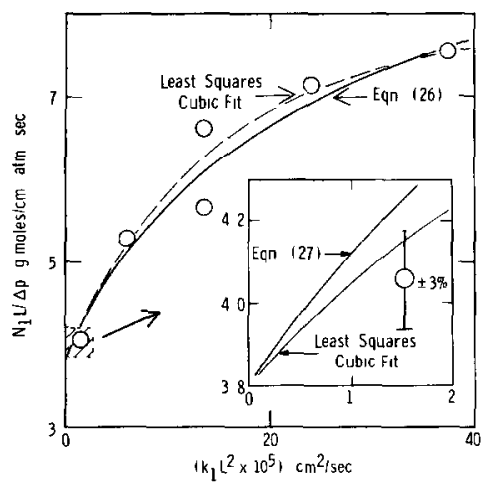

Fig 5 Effective permeability of $\mathrm{CO}_{2}$ through bicarbonate solution as a function of $k_{1} L^{2}$

film of $\frac{2}{3}$ atm were obtained by interpolation These results are plotted in Fig 5 in accordance with the co-ordinates of Eq (30) using a diffusion thickness per Gelman membrane of $200 \mu$ A numerical solution to Eq (26) as well as a least-squares cubic fit are included in Fig 5 for comparison Based on the correction terms given in Table 1 , we note that for Eq (30) to be valid, $\alpha^{2} \leq 083$ The extrapolated intercept at $k_{1} L^{2} \rightarrow 0$ is

$$
D_{1} H_{1}=38 \pm 01 \times 10^{-10} \text { moles } / \mathrm{cm}, \text { atm, sec }
$$

The difference between this value of permeability for $\mathrm{CO}_{2}$ in $1 \mathrm{~N} \mathrm{NaHCO}-\mathrm{Na}_{2} \mathrm{CO}_{3}$ solution and that for $\mathrm{CO}_{2}$ in water $\left(668 \times 10^{-10}\right)$ is a result of the effect of chemical composition on permeability

\section{DISCUSSION}

Estımates for the permeability of carbon dioxide in $1 \mathrm{~N} \mathrm{NaHCO}-\mathrm{Na}_{2} \mathrm{CO}_{3}$ solution, based on literature correlations for gas diffusivity and solubility in electrolytes, are given in Table 2 The procedure used was to correct the values of $D_{1}^{\circ}$ and $H_{i}^{\circ}$ given earlier for the effects of viscosity on the diffusivity and the Ionic strength on solubility of carbon dioxide

A problem which immediately arıses in implementing this procedure is that the composition of the solution is not known exactly, since the relative ratio of $\mathrm{NaHCO}_{3}$ to $\mathrm{Na}_{2} \mathrm{CO}_{3}$ will depend on the carbon dioxide partial pressure Therefore, in order to use these literature correlations, one must turn to the theoretical analysis presented in this paper Based on Eqs (28a) and (28b), we estımate that about 94 per cent of the carrier is in the form of bicarbonate ion (that $1 \mathrm{~s}, \gamma_{3}{ }^{(0)}=0$ 94)
For estımatıng carbon dioxide diffusivity, literature correlations based on viscosity of the solution were used

$$
\frac{D_{1}}{D_{1}^{\circ}}=\eta^{-m}
$$

where $\eta$ is the viscosity of the solution, relative to the solvent, and the empirical factor $m$, and carbon dioxide diffusivities calculated therefrom, are as follows

$\begin{array}{lcc}\text { Source } & m & D_{1} \times 10^{5}, \mathrm{~cm}^{2} / \mathrm{sec} \\ \text { Wilke-Chang[22] } & 1 & 156 \\ \text { Nysing-Kramers[4] } & 085 & 162 \\ \text { Ratcliff-Holdcroft[1] } & 0637 & 170\end{array}$

For the solution under study $\left(\gamma_{3}{ }^{(0)}=094\right)$, a relative viscosity of 126 was estumated from the viscosity data in International Critical Tables [23]

For estımatıng carbon dioxıde solubility, the correlation of van Krevelen and Hoftizer [3] for predicting solubility of gases in non-reacting electrolytic solutions was used, the decrease in the solubility due to added salt is given by

$$
\log \frac{H_{1}}{H_{1}^{\circ}}=-h I
$$

where $I$ is the ionic strength of the electrolyte, and $h$ is defined as the sum of contributions of various species

$$
h=h_{+}+h_{-}+h_{g}
$$

For a $1 \mathrm{~N} \mathrm{NaHCO}-\mathrm{Na}_{2} \mathrm{CO}_{3}\left(\gamma_{3}{ }^{(0)}=094\right)$, the values for $h$ and $I$ are 0098 [3] and 103 , respectively

The discrepancy between the various values of carbon dioxide permeability given in Table 2 remains unexplained The work of Danckwerts and Kennedy [6] on absorption of carbon dioxide in neutral solutions $\left(\mathrm{NaSO}_{4}, \mathrm{MgSO}_{4}\right)$ indicates that the diffusivity of carbon dioxide in these solutions is less than or equal to that predicted by the Wilke-Chang correlation [22] On the other hand, the work of Roberts and Danckwerts [5] on carbon dioxide absorption conforms to the Ratcliff-Holdcroft correlation[1] Otto and Quinn [13] report a value of 09 for the ratio of observed carbon dioxide flux to the calculated Fick's Law flux (based on the diffusivity correlation of Wilke-Chang (that is, $m=1$ ) and solubility correlations of van Krevelen and Hoftizer) This conforms to our findıngs and further suggests that the use of a porous, tortuous membrane is not the only cause of our 
lower observed permeability value Otto and Quinn[13] indicate that the discrepancy is possibly a result of inaccuracies in the viscosity data given in the literature

Theoretically, the solubility of carbon dioxide can be estımated from the slope, near the origin, of the curve in Fig 5 In the event that the first order correction term in the series is dominant, Eq (27) reduces to $\mathrm{Eq}(30)$, and Henry's Law constant is given by

$$
H_{1}=\text { Slupe } \times \frac{12}{Y_{0}}
$$

However, estimating the true limiting slope may be subject to errors in cases where the second-order correction term is a significant fraction of the firstorder correction term One therefore must determine the permeability from plots such as Fig 4, and thereafter use Eq (27) in the form of Fig 2 to estimate $D_{1}$ and $H_{1}$ individually Unfortunately, plots such as Fig 2 demand a very high degree of accuracy in flux measurements for small values of facilitation factor $F$, for example, a 5 per cent error in carbon dioxide flux at a diffusion length of $200 \mu$ results in an error in $F$ value of $50-100$ per cent

In the final analysis, one concludes that a farly accurate determination of permeability may be obtained by the procedure outlined herein It is noted that the criterion for such determinations is not that the reaction be virtually absent (that is, $\alpha \ll 1$ ), but that a small, although finite, reaction rate is permissible (that 1s, $\alpha<\alpha_{c}$ ) When $\alpha_{c} \gg 1$, we note that fairly accurate estimates of diffusivity and solubility could have been obtained for the case under study However, for the experimental situation described here $\left(\alpha_{c} \sim 08\right)$ the estimates of individual values that make up the permeability term, namely, diffusivity and solubility, are subject to large errors and are therefore not included

An alternate method for permeability determination via the "carner" facilitated mechanism described here seems proper as a closing remark In cases where the critical value of diffusion-reaction parameter $\alpha_{c}$ results in too small a film thickness, one may eliminate the facilitation effect, that is, the gradient in "carrier" concentratıons, by operatıng at sufficiently high upstream and downstream gas pressures For example, in the transfer of oxygen across a $150 \mu$ film containing hemoglobin, a minımum oxygen partial pressure of $40 \mathrm{mmHg}$, that is $\bar{p}_{0}, \quad p_{1} \geq 40 \mathrm{mmHg}$, is sufficient to transform hemoglobin completely into the oxy-hemoglobin form Thus, the flux of oxygen across such a hemoglobin film for $\bar{p}_{o}>p_{1} \geq 40 \mathrm{mmHg}$ would represent the 'Fickian' flux and thereby permit reasonable estımation of oxygen permeability through such reacting solutions This concept has been utilized by Keller and Friedlander[24] as well as Kutchar and Staub[25]

Acknowledgements - This work was partially supported by the National Institutes of Health, Grant GM-15152, and Research Career Development Award (No IKOGMO8271) to J S Schultz, the support of the Dutch science Foundation, Z W O while $J$ S Schultz was a visiting professor at the University of Nijmegen is gratefully acknowledged

\section{NOTATION}

A. species 1

$\hat{C}_{1}$ concentration of $A_{1}$, moles $/ \mathrm{cm}^{3}$

$C_{t}$ dimensionless concentration of $A_{1}$

$\hat{C}_{1}(0), \hat{C}_{1}(1)$ concentration of transferred species at $y=0, L$, respectively, moles $/ \mathrm{cm}^{3}$

$C_{3}{ }^{T}$ total "carrier" concentration, moles $/ \mathrm{cm}^{3}$

$D_{1}$ binary diffusivity of $A_{1}, \mathrm{~cm}^{2} / \mathrm{sec}$

$F$ facilitation factor defined in Eq (29)

$f$ integral defined in Eq (16)

$g$ ratio of stoichiometric to diffusion terms

$H_{1}$ solubility of carbon dioxide, moles $/ \mathrm{cm}^{3}$, atm

$K$ overall equilibrium constant for $\mathrm{CO}_{2} / \mathrm{HCO}_{3}{ }^{-} / \mathrm{CO}_{3}{ }^{2-}$ reactions

$K_{3}, K_{w}$ equilibrium constants for reaction Eq (24)

$k_{\imath}, k_{-1}$ rate constants for reaction Eq (23)

$k_{L}$ liquid mass transfer coefficient, $\mathrm{cm} / \mathrm{sec}$

$L$ diffusion path length, cm

$m$ equilibrium constant defined in $\mathrm{Eq}$ (26)

$N_{0}$ "Fickıan" flux, moles $/ \mathrm{cm}^{2}$, sec

$N_{1}$ reaction facilitated flux, moles $/ \mathrm{cm}^{2}$, sec

$n$ hydroxyl ion effect defined in Eq (25)

$\bar{p}, \underline{p}$ partial pressure of $A_{1}$ at $y=0, L$, respectively, atm

$r_{t} \quad$ rate of depletion of $A_{1}$, moles $/ \mathrm{cm}^{3}$, sec

$t_{D}, t_{R}$ half times for diffusion and reaction, respectively, sec

$x$ dimensionless distance

$y$ distance variable within the film, $\mathrm{cm}$

\section{Greek symbols}

$\alpha$ ratio of reaction of diffusion term

$\gamma_{1}$ constant of integration defined in Eq 
$\delta$ perturbation coefficient of reaction rate defined in $\mathrm{Eq}$ (11)

$\epsilon_{\imath}$ constant of integration defined in Eq (15)

$\lambda$ integral defined in Eq (20)

$\nu_{t}$ stoichrometric ratio for $A_{t}$

$\phi$ dimensionless kınetic function

\section{Superscripts}

(k) $k$ th order perturbation parameter

0 for estimation in water

\section{REFERENCES}

[1] RATCLIFF G A and HOLDCROFT J G, Trans Instn Chem Engrs 196341315

[2] NYSING R A T O et al, Chem Engng Scı 195910 88

[3] VAN KREVELEN D W and HOFTIZER P J, Chimı Ind Numero Speciale du XXIe Congress International de Chımı, Industriell, Bruxelles, Sept 1948,1968

[4] NYSING R A T O and KRAMERS H, Chem Engng $\mathrm{Scl} 1958881$

[5] ROBERTS D and DANCKWERTS P V, Chem Engng Scl 196217961

[6] DANCKWERTS $P$ V and KENNEDY A $M$, Chem Engng Scl 19588201

[7] DANCKWERTS P V, Gas-Liquid Reactions, Chapt 6 McGraw-Hill, New York 1970

[8] SCHOLANDER P F, Science 1960131585

[9] HEMMINGSEN E A and SCHOLANDER P F, Science 19601321379

[10] CRANK J, The Mathematics of Diffusion, p 145 Oxford University Press, London 1964

[11] SUCHDEO S R and SCHULTZ J S , Chem Engng Prog Symp Ser 197167 (114) 165

[12] SMITH K A, MELDON J H and COLTON C K , A I Ch E Jl 197319102

[13] OTTO N C and QUINN J A, Chem Engng Scl 197126949

[14] GIBBONS B H and EDSALL J T, $J$ Biol Chem, 19632383502

[15] MCCOY H N, Am J Chem 190329437

[16] ROBINSON R A and STOKES R H, Electrolyte Solutions, Chapts 6 and 11 Academic Press, New York 1955

[17] BASSET R J and SCHULTZ J S, Bochım Biophys Acta 1970211194

[18] Chemical Engineer's Handbook (Eds PERRY R H , et al) p 14-5 McGraw-Hill, New York 1963

[19] PLEVAN R E and QUINN J A, A I Ch E Jl 1966 12894

[20] HIMMELBLAU D M, Chem Rev 196464527

[21] WITTENBERG J B , Physiol Rev 197050 (4) 559

[22] WILKE C R and CHANG P, A I Ch E Jl 19551 264

[23] International Cntical Tables, Vol 5 National Research Council, McGraw-Hill, New York 1933

[24] KELLER K H and FRIEDLANDER S K, J Gen Physiol 196649663

[25] KUTCHAI H and STAUB N C, J Gen Physiol 196953576

\section{APPENDIX 1}

Solution to Eq (26) for $\alpha \rightarrow 0$

$$
\frac{\mathrm{d}^{2} C_{\mathrm{i}}}{\mathrm{d} x^{2}}=g_{i} \alpha^{2} \phi
$$

\section{Zero-order term}

$$
\begin{aligned}
& \delta^{(0)}=0 \\
& C_{1}^{(0)}=1-(1-\rho) x \\
& C_{2}^{(0)}=\gamma_{2}^{(0)} \\
& C_{3}^{(0)}=\gamma_{3}{ }^{(0)} \\
& \gamma_{3}^{(0)}+2 \gamma_{2}{ }^{(0)}=1
\end{aligned}
$$

A second relationship between $\gamma_{2}{ }^{(0)}$ and $\gamma_{3}{ }^{(0)}$ is obtained by solving for the

First-order term

$$
\begin{aligned}
\delta^{(1)} & =Y_{0}\left[1-(1-\rho) x-m \frac{\gamma_{3}^{(0) 2}}{2 \gamma_{2}{ }^{(0)}}\right] \\
f^{(1)} & =\int \delta^{(1)} \mathrm{d} \bar{x} \\
& =Y_{0}\left[x-(1-\rho) \frac{x^{2}}{2}-m \frac{\gamma_{3}^{(0) 2}}{2 \gamma_{2}{ }^{(0)}} x\right]
\end{aligned}
$$

At $x=0, f^{(1)}=f_{0}^{(1)}=0$

At $x=1, f^{(1)}=f_{1}^{(1)}$

$$
=\left[\frac{1+\rho}{2}-m \frac{\gamma_{3}{ }^{(0) 2}}{2 \gamma_{2}{ }^{(0)}}\right]
$$

$f_{0}^{(1)}=f_{1}^{(1)}$ gives

$$
\frac{\gamma_{3}^{(0) 2}}{\gamma_{2}{ }^{(0)}}=\frac{1+\rho}{m}
$$

Substituting Eq (1 4) into Eq (1 3), we have

$$
f^{(1)}=-a Y_{0} / 2\left(x-x^{2}\right)
$$

Therefore

$$
\begin{aligned}
\lambda^{(1)} & =\int f^{(1)} \mathrm{d} x \\
& =-a Y_{0} / 12\left(3 x^{2}-2 x^{3}\right)
\end{aligned}
$$

At $x=0$,

$$
\begin{aligned}
\lambda^{(1)} & =\lambda_{1}{ }^{(1)} \\
& =-a Y_{0} / 12
\end{aligned}
$$

The first-order concentration profiles for $D_{2}=D_{3}$, are

$$
C_{i}^{(1)}=g_{i} \lambda^{(1)}+\epsilon_{i}^{(1)} x+\gamma_{i}^{(1)}
$$

where

$$
\begin{gathered}
\lambda^{(1)}=-a Y_{0} / 12\left(3 x^{2}-2 x^{3}\right) \\
\epsilon_{1}^{(1)}=-g_{1} \lambda_{1}{ }^{(1)}, \gamma_{1}^{(1)}=0 \\
\epsilon_{2}^{(1)}=\epsilon_{3}{ }^{(1)}=0 \\
\gamma_{3}^{(1)}+2 \gamma_{2}{ }^{(1)}=0
\end{gathered}
$$


A second relationshıp between $\gamma_{2}{ }^{(1)}$ and $\gamma_{3}{ }^{(1)}$ is obtained by solving for the

Second-order term

$$
\begin{aligned}
\delta^{(2)}= & Y_{0} C_{1}{ }^{(1)}+\left[Y_{1}-a Y_{2}\left(x-\frac{1}{2}\right)\right] C_{2}{ }^{(1)} \\
f^{(2)}= & \int \delta^{(2)} \mathrm{d} x \\
= & a Y_{0}^{2} / 24\left(x^{2}-2 x^{3}+x^{4}\right) \\
& +a g_{2} Y_{0} Y_{1} / 24\left(x^{4}-2 x^{3}\right) \\
& -a^{2} g_{2} Y_{0} Y_{2} / 120\left(5 x^{3}-10 x^{4}+4 x^{5}\right) \\
& +\gamma_{2}^{(1)}\left[Y_{1} x-a Y_{2} / 2\left(x^{2}-x\right)\right]
\end{aligned}
$$

Thus,

treated as constants

At $x=0, f^{(2)}=f_{0}^{(2)}=0$

At $x=1, f^{(2)}=f_{1}^{(2)}$

$$
=-a g_{2} Y_{0} Y_{1} / 24+a^{2} g_{2} Y_{0} Y_{2} / 120+\gamma_{3}{ }^{(1)} Y_{1}
$$

Further, $f_{0}^{(2)}=f_{i}^{(2)}$ glves

$$
\gamma_{3}^{(1)}=a g_{2} / 24\left(1-\frac{a \zeta}{5}\right)
$$

Integrating Eq (19), we have

$$
\begin{aligned}
\lambda^{(2)}= & \int f^{(2)} \mathrm{d} x \\
= & a Y_{0}{ }^{2} / 720\left(10 x^{3}-15 x^{4}+6 x^{5}\right) \\
& +a g_{2} Y_{0} Y_{1} / 240\left(2 x^{5}-5 x^{4}\right) \\
& -a^{2} g_{2} Y_{0} Y_{2} / 1440\left(8 x^{6}-24 x^{5}+15 x^{4}\right) \\
& +\gamma_{3}^{(1)} / 2\left[Y_{1} x^{2}-a Y_{2} / 6\left(2 x^{3}-3 x^{2}\right)\right]
\end{aligned}
$$

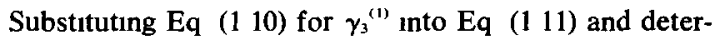
minıng at $x=1$, we have

$$
\lambda_{1}^{(2)}=a Y_{0} / 720\left[Y_{0}+g_{2} Y_{1}\left(6-\frac{(a \zeta)^{2}}{2}\right)\right]
$$

The second-order concentration profiles need be determined only if the third-order correction term is desired Up to second-order correction term,

$$
\frac{N_{1}}{N_{0}}=1+\frac{\lambda_{1}^{(1)} \alpha^{2}+\lambda_{1}^{(2)} \alpha^{4}}{(1-\rho)}+0\left(\alpha^{6}\right)
$$

where

$$
\begin{aligned}
& \lambda_{1}{ }^{(1)}=(1-\rho) Y_{0} / 12 \\
& \lambda_{1}{ }^{(2)}=-(1-\rho) Y_{0} / 720\left[Y_{0}+g_{2} Y_{1}\left(6-\frac{a^{2} \zeta^{2}}{2}\right)\right]
\end{aligned}
$$

\section{APPENDIX 2}

Constant carrier concentration an approxtmation Recalling the diffusion-reaction equation, namely,

$$
\frac{\mathrm{d}^{2} C_{i}}{\mathrm{~d} x^{2}}=g_{i} \alpha^{2} \phi
$$

it is assumed that under limiting conditions, the concentration of the carrier species, that is, $C_{2}$ and $C_{3}$, may be

$$
\begin{aligned}
& C_{2}=\gamma_{2}{ }^{\left({ }^{(0)}\right.} \\
& C_{3}=\gamma_{3}{ }^{(0)}
\end{aligned}
$$

$$
\frac{\mathrm{d}^{2} C_{1}}{\mathrm{~d} x^{2}}=\alpha^{2} Y_{0}\left(C_{1}-m \frac{\gamma_{3}{ }^{(0) 2}}{2 \gamma_{2}{ }^{(0)}}\right)
$$

The solution to the ordinary differential equation, Eq (2 2), is

$$
\begin{aligned}
C_{1}= & M_{1} \cosh \left(\alpha \sqrt{Y_{0}} x\right) \\
& +M_{2} \sinh \left(\alpha \sqrt{Y_{0}} x\right) \\
& +m \frac{\gamma_{3}{ }^{(0) 2}}{2 \gamma_{2}{ }^{(0)}}
\end{aligned}
$$

The four unknowns, $\gamma_{3}^{(0)}, M_{1}, M_{2}, \gamma_{2}{ }^{(0)}$ and $\gamma_{3}{ }^{(0)}$, are determined from the following conditions

$$
\begin{aligned}
& C_{1}=1 @ x=0 \\
& C_{1}=\rho @ x=1
\end{aligned}
$$

$$
\left.\begin{array}{c}
{\left[\frac{\mathrm{d} C_{1}}{\mathrm{~d} x}\right]_{\bar{x}=0}=\left[\frac{\mathrm{d} C_{1}}{\mathrm{~d} x}\right]_{x=1}} \\
\int_{0}^{1}\left(C_{3}+2 C_{2}\right) \mathrm{d} x=1
\end{array}\right\}
$$

Thus,

$$
\begin{gathered}
\frac{\gamma_{3}{ }^{(0) 2}}{\gamma_{2}{ }^{(0)}}=\frac{1+\rho}{m} \\
M_{1}=-M_{2} \tanh \left(\frac{1}{2} \alpha \sqrt{Y_{0}}\right) \\
M_{2}=-(1-\rho) / 2 \operatorname{coth}\left(\frac{1}{2} \alpha \sqrt{Y_{0}}\right) \\
\gamma_{3}{ }^{(0)}+2 \gamma_{2}{ }^{(0)}=1
\end{gathered}
$$

The flux of carbon dıoxıde relatıve to its Fickıan flux is

$$
\begin{aligned}
\frac{N_{\mathrm{t}}}{N_{0}} & =-\frac{1}{(1-\rho)}\left[\frac{\mathrm{d} C_{1}}{\mathrm{~d} x}\right]_{x=0} \\
& \approx \frac{-\alpha \sqrt{Y_{0}}}{(1-\rho)} M_{2}
\end{aligned}
$$

Substıtutıng for $M_{2}$, we have

$$
\frac{N_{1}}{N_{0}}=\frac{\alpha \sqrt{Y_{0}}}{2} \operatorname{coth}\left(\frac{\alpha \sqrt{Y_{0}}}{2}\right)
$$

In the limit, that $1 s, q \leqslant 1$

$$
q \operatorname{coth} q \simeq 1+q^{2} / 3
$$

Hence,

$$
\frac{N_{1}}{N_{0}} \simeq 1+\frac{1}{12} \alpha^{2} Y_{0}
$$

